\title{
Oral human papillomavirus infection in HIV-infected and HIV-uninfected MSM: the OHMAR prospective cohort study
}

\author{
Massimo Giuliani, ${ }^{1}$ Francesca Rollo, ${ }^{2}$ Maria Fenicia Vescio, ${ }^{3}$ Barbara Pichi, ${ }^{4}$ \\ Alessandra Latini (1), ${ }^{1}$ Maria Benevolo, ${ }^{2}$ Raul Pellini, ${ }^{4}$ Antonio Cristaudo, ${ }^{1}$ \\ Maria Gabriella Dona' (1) ${ }^{1}$
}

\begin{abstract}
- Additional material is published online only. To view, please visit the journal online (http://dx.doi.org/10.1136/ sextrans-2019-054301).

${ }^{1}$ STI/HIV Unit, San Gallicano Dermatological Institute IRCCS, Rome, Italy

${ }^{2}$ Pathology Department, Regina Elena National Cancer Institute IRCCS, Rome, Italy

${ }^{3}$ Department of Infectious, Parasitic and Immunomediated Diseases, Istituto Superiore di Sanità, Rome, Italy

${ }^{4}$ Otolaryngology Head and Neck Surgery Department, Regina Elena National Cancer Institute IRCCS, Rome, Italy
\end{abstract}

\section{Correspondence to}

Dr Maria Gabriella Dona', STI/HIV Unit, San Gallicano Dermatological Institute IRCCS, Rome 00144, Italy; mariagabriella.dona@ifo.gov.it

$\mathrm{AC}$ and MGD' contributed equally.

Received 1 October 2019 Revised 30 December 2019 Accepted 12 January 2020 Published Online First 30 January 2020

\section{Check for updates}

(C) Author(s) (or their employer(s)) 2020. No commercial re-use. See rights and permissions. Published by BMJ.

To cite: Giuliani $\mathrm{M}$,

Rollo F, Vescio MF

et al. Sex Transm Infect

2020;96:528-536.

\section{ABSTRACT}

Objective We aimed to assess incidence and clearance of oral human papillomavirus (HPV) infection and the respective risk factors in HIV-infected and uninfected men who have sex with men (MSM).

Methods Oral rinse and gargles were collected semiannually from 244 MSM (103, 42.2\% HIV-infected). HPV-DNA testing was performed with the Linear Array HPV Genotyping test. A Markov model was used for estimation of incidence, clearance and risk factor analysis.

Results Incidence rates for any HPV were 21.2 and $15.0 \times 1000$ person-months in HIV-infected and uninfected MSM, respectively. The respective figures for high-risk HPVs were 10.7 and $6.5 \times 1000$ person-months. The clearance rate was 4-12 times higher than the respective incidence rate. HIV-infected MSM with >95 lifetime oral sex partners showed increased incidence of any HPV (adjusted HR, aHR: $8.46,95 \% \mathrm{Cl} 1.89$ to 37.92). Condomless oral sex appeared the strongest predictor for incident infection by high-risk HPVs in this group (aHR: $13.40,95 \% \mathrm{Cl} 2.55$ to 70.53). Those aged $>46$ years (aHR: $0.30,95 \% \mathrm{Cl} 0.12$ to 0.74 ) and those with nadir CD4+ T count of $<200$ cells $/ \mathrm{mm}^{3}$ (aHR: 0.14 , $95 \% \mathrm{Cl} 0.03$ to 0.75 ) displayed a significantly reduced clearance of any and high-risk HPVs, respectively. HIVuninfected MSM aged $>46$ years had increased risk of acquiring any HPV (aHR: $3.70,95 \% \mathrm{Cl} 1.30$ to 10.52 ) and high-risk HPV (aHR: $5.33,95 \% \mathrm{Cl} 1.06$ to 26.68). Any HPV clearance declined in those with more than six recent oral sex partners (aHR: $0.18,95 \% \mathrm{Cl} 0.05$ to 0.65).

Conclusions Acquisition of oral HPV infection in MSM seems to occur rarely, whereas clearance seems to be a frequent event. Oral HPV natural history in these atrisk subjects is differently influenced by age and sex behaviour, depending on HIV status.

\section{INTRODUCTION}

A great focus has been recently placed on the epidemiology of oral human papillomavirus (HPV) infection due to its role in the development of oropharyngeal cancer (OPC). ${ }^{12}$ A large study has estimated a worldwide HPV-attributable fraction of $21.8 \%,{ }^{1}$ with the highest figures observed in Northern Europe and the USA, where more than
$40 \%$ of the cases are driven by HPV. ${ }^{12}$ Notably, a continuous rise in the incidence of HPV-associated OPC has been observed in several countries. ${ }^{3-5}$

Oral HPV infection is rare in the general population, with an overall prevalence of $5 \%-8 \%$ and of $2.0 \%-3.5 \%$ for oncogenic types. ${ }^{67} \mathrm{~A}$ twofold to threefold increased prevalence is observable in men who have sex with men (MSM), ${ }^{6-10}$ with a further increase in HIV-infected subjects. ${ }^{811-13}$ Despite the discrete number of cross-sectional studies, longitudinal studies on oral HPV infection remain scarce. Consequently, the natural history of this infection is largely unknown. The understanding of the dynamics of the infection and the factors involved in its acquisition and persistence would help plan effective strategies to prevent oral HPV and to counter the rising incidence of HPV-associated OPC.

A few longitudinal studies investigated oral HPV natural history in cohorts of MSM, ${ }^{14-17}$ but only two studies, both conducted on the same cohort, made a direct comparison of incidence and clearance in HIV-infected and uninfected MSM. ${ }^{15} 18$ To improve the knowledge of the dynamics of oral HPV infection in these populations, we conducted a prospective cohort study on HIV-infected and uninfected MSM, estimating incidence and clearance rates of any, high-risk and type-specific HPV infections. Risk factors for acquisition and clearance were also investigated separately by HIV status.

\section{METHODS}

\section{Study population and data collection}

Participants were recruited among attendees of the STI/HIV centre of the San Gallicano Dermatological Institute (Rome, Italy) between November 2014 and February 2018. Inclusion criteria for the Oral $\underline{H P V}$ in $\underline{\text { Men }} \underline{\text { At }} \underline{\text { Risk (OHMAR) study have }}$ been previously described. ${ }^{10}$ Briefly, MSM aged $\geq 18$ years were recruited if they had no history of head and neck cancer (HNC) and no lesions that were clinically suspicious for HNC. At baseline and each semiannual follow-up visit, a thorough clinical evaluation of the oral cavity and the oropharynx was performed by expert otolaryngologists, who also rated oral health/hygiene. 
At each visit, sociodemographic information, data on lifestyle, lifetime and recent (last 6 months) sexual behaviour were collected through face-to-face interviews. Recall bias was minimised by reducing collection of lifetime behavioural data. Relevant data on the HIV-infected MSM were retrieved from medical records.

\section{Oral rinse-and-gargle collection}

Participants used $15 \mathrm{~mL}$ of Listerine mouthwash to rinse and gargle for $30 \mathrm{~s}$. The expectorate was immediately placed on ice and centrifuged within $30 \mathrm{~min}$. The cell pellet was resuspended in $2 \mathrm{~mL}$ of PreservCyt (Hologic, Pomezia, Italy) and $250 \mu \mathrm{L}$ aliquots for HPV-DNA testing were stored at $-80^{\circ} \mathrm{C}$ until used.

\section{HPV detection and genotyping}

The Linear Array HPV Genotyping test (Roche Diagnostics, Milan, Italy) was used, following the manufacturer's instructions. Briefly, $50 \mu \mathrm{L}$ of the nucleic acids extracted from the PreservCyt sample was used for amplification. The human betaglobin gene provided a control for cell adequacy, extraction and amplification for each processed sample. A beta-globin DNA probe, immobilised on each strip at low and high concentrations, provided a control for hybridisation and detection steps, performed in the Profiblot T48 (Tecan, Männedorf, Switzerland). Results were interpreted as indicated by the producer (ie, the test was considered valid whenever beta-globin hybridisation bands and/or at least one HPV hybridisation band was detected).

\section{Statistical analysis}

We estimated that 142 subjects had to be followed up for 12 months to test the null hypothesis $(\mathrm{H} 0): \lambda=4.38 \times 1000 \mathrm{p}-\mathrm{m}$ (incidence rate in the heterosexual population) ${ }^{6}$ vs the alternative hypothesis (HA): $\lambda=6.65 \times 1000 \mathrm{p}-\mathrm{m}$ (incidence rate in the $\mathrm{HIV}$-infected MSM, ie, 1.5 times the incidence rate under $\mathrm{H} 0$ ) with a significance level of $5 \%$ and power of $80 \%$.

Descriptive statistical techniques were used to provide summarised characteristics of the participants. Drinking habits were classified as previously described. ${ }^{10}$ The oral health/hygiene was rated by the otolaryngologists who performed the oral examinations using a scoring system based on six parameters (online supplementary appendix 1). An index was also calculated for selfreported oral care/condition, attributing a score to the responses given during the interview (online supplementary appendix 1). Baseline sociobehavioural characteristics of the HIV-infected and HIV-uninfected MSM were compared using $\chi^{2}$ tests.

Incidence and clearance rates were assessed separately for HIV-infected and HIV-uninfected MSM and were computed for (1) any HPV: at least 1 of the $37 \mathrm{HPV}$ detectable by the Linear Array; (2) high-risk HPVs: at least 1 genotype among 16, 18, $31,33,35,39,45,51,52,56,58,59,66$ and 68, regardless of the presence of other types; and (3) the individual high-risk genotypes. Incidence and clearance were estimated jointly using a two-state homogeneous Markov model for interval-censored event data ${ }^{19}$ (online supplementary appendix 2). The transition rate from one state to another was assumed to be constant over time. Incidence was modelled as the rate of transition per month from an HPV-negative (0) to an HPV-positive state (1). Clearance was defined as lack of detection at visit $\mathrm{x}$ of the HPV(s) detected at visit $\mathrm{x}-1$, that is, 6 months before, and modelled as the rate of transition from an HPV-positive (1) to an HPV-negative state (0). Prevalent infections were included when estimating the transition intensity from HPV-positive to HPV-negative states.
More than one incident infection or cleared infection within one participant was allowed.

Demographic characteristics, behavioural factors, clinical history and HIV-related immunological parameters were all taken into account in the risk factor analysis for incidence and clearance. The variables that resulted significantly associated with incidence and/or clearance from the univariate analysis $(\mathrm{p}<0.20)$ were then included in the multivariable model. Likelihood ratio tests were used to obtain more parsimonious models. Risk factor analysis was conducted separately for any HPV and high-risk HPVs, and separately for HIV-infected and uninfected MSM. For the purposes of analysis, oral health/hygiene, smoking, age and number of partners for any and oral sex were categorised as described in online supplementary appendix 1 . Whenever the model failed to converge because of a specific variable, that variable was excluded from the model. This was the case for condom use in oral sex, which was excluded from the model for any and high-risk HPVs in HIV-uninfected MSM.

Time-dependent covariates were assumed to be piecewiseconstant. Statistical analyses were conducted using STATA V.13 and R V.3.0.2 (http://www.r-project.org, R Core Team 2014).

\section{RESULTS}

\section{Study population}

A total of 310 MSM, of which 117 were HIV-infected (37.7\%), were recruited. Sixty-six individuals (21.3\%) attended only the baseline visit (they refused to come back or moved during the study period), whereas $244(78.7 \%)$ returned for at least one follow-up visit (range: 1-5, median: 2; median follow-up time: 13 months, IQR: 10-19). The final group (97.1\% Caucasian) included $103 \mathrm{HIV}$-infected (compliance rate: 88.0\%) and 141 HIV-uninfected (compliance rate: 73.0\%) individuals for a total of 856 oral rinses collected. The longitudinal cohort did not differ significantly from the MSM that only had the baseline sampling regarding the sociodemographic and sexual behavioural characteristics, except for the higher number of lifetime oral sex partners (median 50 vs $28, \mathrm{p}=0.033$ ) and more frequent STI history $(73.8 \%$ vs $60.6 \%, \mathrm{p}=0.037)$ in the former group (data not shown).

The baseline sociodemographic and behavioural characteristics of the study subjects are shown in table 1 .

Most of the HIV-infected individuals were under combined antiretroviral therapy (cART) $(96 / 103,93.2 \%)$. Of the cARTtreated subjects, 89 (92.7\%) had an undetectable HIV-1 RNA load. The median numbers of nadir and current CD4+ T-cell counts were 300 (IQR: 228-387) and $636 \mathrm{cells} / \mathrm{mm}^{3}$ (IQR: 485-807), respectively (data not shown).

\section{Incidence and clearance of oral HPV infection}

A valid HPV test result was obtained for all the oral samples analysed. Incidence and clearance rates for any HPV, high-risk HPVs and the individual high-risk types are shown in table 2.

\section{Risk factors for incidence and clearance of oral HPV infection}

The univariate and multivariate analyses for incidence and clearance of any HPV are shown in table 3A. In HIV-infected MSM, all the associations observed in the univariate analysis were confirmed at multivariate analysis. Incidence significantly increased in those with $>95$ compared with $<25$ lifetime oral sex partners (aHR: 8.46, 95\% CI 1.89 to 37.92). Clearance significantly decreased in those aged $>46$ years (aHR: 0.30 , 95\% CI 0.12 to 0.74$)$. 
Table 1 Baseline sociodemographic and behavioural characteristics of the 244 MSM included in the longitudinal cohort, overall and stratified according to HIV status

\begin{tabular}{|c|c|c|c|c|c|c|c|}
\hline \multicolumn{3}{|c|}{$\begin{array}{ll}\text { Overall } \\
\mathrm{n}=244\end{array}$} & \multicolumn{2}{|c|}{$\begin{array}{l}\text { HIV-infected } \\
\mathrm{n}=103\end{array}$} & \multicolumn{2}{|c|}{$\begin{array}{l}\text { HIV-uninfected } \\
\mathrm{n}=141\end{array}$} & P value* \\
\hline \multicolumn{7}{|l|}{ Age (years) } & 0.289 \\
\hline $36-46$ & 85 & 34.8 & 37 & 35.9 & 48 & 34.0 & \\
\hline$>46$ & 80 & 32.8 & 38 & 36.9 & 42 & 29.8 & \\
\hline \multicolumn{7}{|l|}{ Education } & 0.024 \\
\hline Postgraduate & 113 & 46.3 & 39 & 37.9 & 74 & 52.5 & \\
\hline \multicolumn{7}{|c|}{ Annual income (euros) } & 0.27 \\
\hline$<12000$ & 94 & 38.5 & 36 & 35.0 & 58 & 41.1 & \\
\hline $12000-24000$ & 121 & 49.6 & 51 & 49.5 & 70 & 49.7 & \\
\hline$>24000$ & 29 & 11.9 & 16 & 15.5 & 13 & 9.2 & \\
\hline \multicolumn{7}{|l|}{ Smoking status } & 0.173 \\
\hline \multicolumn{7}{|c|}{ Alcohol consumption } & 0.463 \\
\hline Heavy & 5 & 2.0 & 1 & 1.0 & 4 & 2.8 & \\
\hline Light/moderate & 78 & 32.0 & 31 & 30.1 & 47 & 33.4 & \\
\hline No & 161 & 66.0 & 71 & 68.9 & 90 & 63.8 & \\
\hline \multicolumn{7}{|c|}{ Number of lifetime partners (any sex) } & 0.544 \\
\hline$<50$ & 78 & 32.0 & 30 & 29.1 & 48 & 34.0 & \\
\hline $50-100$ & 69 & 28.3 & 28 & 27.2 & 41 & 29.1 & \\
\hline$>100$ & 97 & 39.7 & 45 & 43.7 & 52 & 36.9 & \\
\hline \multicolumn{7}{|c|}{ Number of recent partners (any sex) $\dagger$} & $<0.0001$ \\
\hline$<3$ & 81 & 33.2 & 55 & 53.4 & 26 & 18.4 & \\
\hline $3-8$ & 81 & 33.2 & 23 & 22.3 & 58 & 41.2 & \\
\hline \multicolumn{7}{|c|}{ Recent receptive oral sext } & 0.010 \\
\hline No & 22 & 9.0 & 15 & 14.6 & 7 & 5.0 & \\
\hline Yes & 222 & 91.0 & 88 & 85.4 & 134 & 95.0 & \\
\hline \multicolumn{7}{|c|}{ Number of recent partners (receptive oral sex) $\ddagger$} & 0.003 \\
\hline$<3$ & 84 & 37.8 & 45 & 51.1 & 39 & 29.1 & \\
\hline $3-8$ & 81 & 36.5 & 27 & 30.7 & 54 & 40.3 & \\
\hline$>8$ & 57 & 25.7 & 16 & 18.2 & 41 & 30.6 & \\
\hline \multicolumn{7}{|c|}{ Occasional partners for recent receptive oral sex $\ddagger$} & $<0.001$ \\
\hline No & 37 & 16.7 & 24 & 27.3 & 13 & 9.7 & \\
\hline Yes & 185 & 83.3 & 64 & 72.7 & 121 & 90.3 & \\
\hline Condom use during & ceptive & & & & & & 0.171 \\
\hline Always & 8 & 3.6 & 5 & 5.7 & 3 & 2.2 & \\
\hline Not always & 214 & 96.4 & 83 & 94.3 & 131 & 97.8 & \\
\hline STI history§ & & & & & & & 0.008 \\
\hline No & 64 & 26.2 & 18 & 17.5 & 46 & 32.6 & \\
\hline Yes & 180 & 73.8 & 85 & 82.5 & 95 & 67.4 & \\
\hline Anogenital wart his & & & & & & & 0.263 \\
\hline No & 159 & 65.2 & 63 & 61.2 & 96 & 68.1 & \\
\hline Yes & 85 & 34.8 & 40 & 38.8 & 45 & 31.9 & \\
\hline Tonsillectomy & & & & & & & 0.316 \\
\hline No & 194 & 79.1 & 85 & 82.5 & 109 & 77.3 & \\
\hline Yes & 50 & 20.9 & 18 & 17.5 & 33 & 22.7 & \\
\hline
\end{tabular}


Table 1 Continued

\begin{tabular}{|c|c|c|c|c|c|c|c|}
\hline & \multicolumn{2}{|c|}{$\begin{array}{l}\text { Overall } \\
n=244\end{array}$} & \multicolumn{2}{|c|}{$\begin{array}{l}\text { HIV-infected } \\
n=103\end{array}$} & \multicolumn{2}{|c|}{$\begin{array}{l}\text { HIV-uninfected } \\
\mathrm{n}=141\end{array}$} & \multirow[t]{2}{*}{ P value* } \\
\hline & $\mathbf{n}$ & $\%$ & $\mathrm{n}$ & $\%$ & $\mathbf{n}$ & $\%$ & \\
\hline Oral care/condition & & & & & & & 0.332 \\
\hline Good & 183 & 75.0 & 74 & 71.8 & 109 & 77.3 & \\
\hline Poor & 61 & 25.0 & 29 & 28.2 & 32 & 22.7 & \\
\hline Oral health/hygiene* * & & & & & & & 0.066 \\
\hline Good/very good & 130 & 53.3 & 46 & 44.6 & 84 & 59.6 & \\
\hline Fair/poor/very poor & 105 & 43.0 & 52 & 50.5 & 53 & 37.6 & \\
\hline Missing & 9 & 3.7 & 5 & 4.9 & 4 & 2.8 & \\
\hline
\end{tabular}

$p$ values for significant differences between the two study groups are indicated in bold.

${ }^{*} \chi^{2}$ test for the comparison between HIV-uninfected and HIV-infected MSM

tDuring the 6 months previous the enrolment.

¥For the subjects who reported receptive oral sex in the previous 6 months.

§Diagnosed at least 6 months prior to enrolment (anogenital warts, syphilis, gonorrhoeae in any site, genital herpes and chlamydia)

ๆSelf-reported and classified on the basis of the answers to six questions concerning oral care and conditions, as specified in the Methods section and in online supplementary appendix 1.

${ }^{* *}$ Ascertained by the otolaryngologist during a full examination of the oral cavity, as detailed in the Methods section and in online supplementary appendix 1.

Table 2 Incidence and clearance rates for oral infection by any HPV, high-risk HPVs and the individual high-risk types for the overall study group and stratified according to HIV status

\begin{tabular}{|c|c|c|c|c|c|c|}
\hline & \multicolumn{2}{|c|}{ Overall } & \multicolumn{2}{|c|}{ HIV-infected MSM } & \multicolumn{2}{|c|}{ HIV-uninfected MSM } \\
\hline & Rate* & $95 \% \mathrm{Cl}$ & Rate* & $95 \% \mathrm{Cl}$ & Rate* & $95 \% \mathrm{Cl}$ \\
\hline \multicolumn{7}{|l|}{ Any HPV } \\
\hline Incidence & 17.8 & 12.4 to 25.4 & 21.2 & 13.0 to 34.7 & 15.0 & 9.0 to 25.2 \\
\hline Clearance & 87.1 & 64.4 to 117.8 & 82.8 & 54.3 to 126.5 & 92.8 & 60.3 to 142.8 \\
\hline \multicolumn{7}{|l|}{ High-risk HPV } \\
\hline Incidence & 8.3 & 5.1 to 13.4 & 10.7 & 5.5 to 20.8 & 6.5 & 3.2 to 13.3 \\
\hline Clearance & 98.4 & 65.7 to 147.5 & 121.1 & 67.7 to 216.8 & 82.7 & 46.6 to 146.8 \\
\hline \multicolumn{7}{|l|}{ HPV16 } \\
\hline Incidence & 2.0 & 0.8 to 4.9 & 0.8 & 0.1 to 5.4 & 3.2 & 1.2 to 8.9 \\
\hline Clearance & 80.9 & 41.9 to 156.2 & 44.8 & 11.2 to 179.3 & 105.5 & 49.6 to 224.2 \\
\hline \multicolumn{7}{|l|}{ HPV33 } \\
\hline Incidence & 1.0 & 0.3 to 3.2 & 1.5 & 0.4 to 6.4 & 0.6 & 0.1 to 4.3 \\
\hline Clearance & 34.7 & 8.7 to 138.3 & 53.1 & 7.6 to 373.3 & 25.7 & 3.6 to 182.0 \\
\hline \multicolumn{7}{|l|}{ HPV39 } \\
\hline Incidence & 1.1 & 0.3 to 3.6 & 0.7 & 0.1 to 5.4 & 1.7 & 0.4 to 8.1 \\
\hline Clearance & 67.9 & 16.9 to 273.1 & 44.4 & 6.2 to 319.2 & 137.7 & 19.4 to 976.7 \\
\hline \multicolumn{7}{|l|}{ HPV51 } \\
\hline Incidence & 0.9 & 0.2 to 4.1 & n.e. & & n.e. & \\
\hline Cearance & 144.9 & 44.3 to 474.7 & n.e. & & n.e. & \\
\hline \multicolumn{7}{|l|}{ HPV56 } \\
\hline Incidence & 0.6 & 0.1 to 4.8 & n.e. & & 1.1 & 0.1 to 9.0 \\
\hline Clearance & 233.5 & 52.9 to 1030.0 & n.e. & & 232.9 & 52.6 to 1031.7 \\
\hline \multicolumn{7}{|l|}{ HPV58 } \\
\hline Incidence & n.e. & & n.e. & & n.e. & \\
\hline Clearance & 99.0 & 13.4 to 731.3 & n.e. & & n.e. & \\
\hline \multicolumn{7}{|l|}{ HPV59 } \\
\hline Incidence & 0.4 & 0.05 to 2.8 & 0.8 & 0.1 to 5.7 & n.e. & \\
\hline Clearance & 80.0 & 25.6 to 250.0 & 57.7 & 14.4 to 231.3 & n.e. & \\
\hline \multicolumn{7}{|l|}{ HPV66 } \\
\hline Incidence & 3.0 & 1.1 to 8.5 & n.e. & & 1.4 & 0.3 to 6.2 \\
\hline Clearance & 245.2 & 97.4 to 617.3 & n.e. & & 78.7 & 11.3 to 549.0 \\
\hline \multicolumn{7}{|l|}{ HPV68 } \\
\hline Incidence & 1.6 & 0.5 to 5.7 & n.e. & & 0.8 & 0.1 to 6.2 \\
\hline Clearance & 205.9 & 76.8 to 552.1 & n.e. & & 128.2 & 31.3 to 524.2 \\
\hline
\end{tabular}

High-risk genotypes for which neither incidence nor clearance could be estimated because zero transitions are not shown.

*Rate is given $\times 1000$ person-months.

HPV, human papillomavirus; MSM, men who have sex with men; n.e., not estimable. 
Table 3 Risk factor analysis for incidence and clearance of oral infection by any HPV (A) and high-risk HPVs (B) in HIV-infected and HIV-uninfected MSM using interval time homogeneous Markov models

\begin{tabular}{|c|c|c|c|c|}
\hline \multirow{2}{*}{$\begin{array}{l}\text { A) Any HPV } \\
\text { HIV-infected MSM }\end{array}$} & \multicolumn{2}{|l|}{ Incidence } & \multicolumn{2}{|l|}{ Clearance } \\
\hline & Univariate $\mathrm{HR}(95 \% \mathrm{Cl})$ & Multivariate aHR $(95 \% \mathrm{Cl})$ & Univariate $\mathrm{HR}(95 \% \mathrm{Cl})$ & Multivariate aHR $(95 \% \mathrm{Cl})$ \\
\hline Age, $>46$ versus $\leq 46$ years $*$ & 0.59 (0.19 to 1.81$)$ & & $0.33(0.14$ to 0.80$)$ & 0.30 (0.12 to 0.74$)$ \\
\hline Education, postgraduate versus undergraduate & 0.55 (0.18 to 1.67 ) & & $0.48(0.20$ to 1.16$)$ & \\
\hline \multicolumn{5}{|l|}{ Pack-yearst } \\
\hline 0 & 1 & & 1 & \\
\hline $0.25-18$ & $1.13(0.33$ to 3.87$)$ & & 0.38 (0.14 to 1.07 ) & \\
\hline$>18$ & 2.20 (0.76 to 6.35$)$ & & 0.84 (0.32 to 2.18$)$ & \\
\hline \multicolumn{5}{|l|}{ Number of lifetime partners for any sex $\ddagger$} \\
\hline$<50$ & 1 & & 1 & \\
\hline $50-150$ & $4.14(0.80$ to 21.44$)$ & & 0.76 (0.19 to 2.98$)$ & \\
\hline$>150$ & 8.84 (1.95 to 40.16$)$ & & 0.65 (0.18 to 2.39 ) & \\
\hline Occasional partners for any sex, yes versus no & 1.38 (0.45 to 4.22$)$ & & $1.58(0.55$ to 4.58$)$ & \\
\hline \multicolumn{5}{|l|}{ Number of lifetime partners for oral sex } \\
\hline$<25$ & 1 & & 1 & \\
\hline $25-95$ & $1.49(0.25$ to 8.95$)$ & 1.58 (0.26 to 9.55$)$ & 1.24 (0.28 to 5.45$)$ & \\
\hline$>95$ & 7.65 (1.71 to 34.14$)$ & 8.46 (1.89 to 37.92$)$ & 0.80 (0.21 to 3.07$)$ & \\
\hline \multicolumn{5}{|l|}{ Number of recent partners for oral sex } \\
\hline$<3$ & 1 & & 1 & \\
\hline $3-6$ & 2.17 (0.70 to 6.82 ) & & 0.81 (0.27 to 2.45 ) & \\
\hline$>6$ & 0.99 (0.25 to 3.98$)$ & & 1.27 (0.47 to 3.41$)$ & \\
\hline Condomless oral sex, yes versus no & $4.27(0.58$ to 31.53$)$ & & n.e. & \\
\hline Oral health/hygiene, poor versus good & 0.72 (0.26 to 1.95$)$ & & 0.49 (0.22 to 1.14$)$ & \\
\hline Oral care/condition, poor versus good & 0.81 (0.29 to 2.29 ) & & 1.46 (0.60 to 3.54$)$ & \\
\hline \multicolumn{5}{|l|}{ STI history } \\
\hline No & 1 & & 1 & \\
\hline Anogenital warts & 1.86 (0.60 to 5.77$)$ & & $0.28(0.04$ to 2.00$)$ & \\
\hline Other STIs & 1.87 (0.61 to 5.75$)$ & & 0.71 (0.29 to 1.75$)$ & \\
\hline Nadir CD4+ T count, $<200$ versus $\geq 200$ cells $/ \mathrm{mm}^{3}$ & 0.59 (0.22 to 1.61$)$ & & $0.52(0.22$ to 1.22$)$ & \\
\hline Current $\mathrm{CD} 4+\mathrm{T}$ count, $<500$ versus $\geq 500$ cells $/ \mathrm{mm}^{3}$ & 0.85 (0.30 to 2.44$)$ & & 0.99 (0.39 to 2.50$)$ & \\
\hline \multicolumn{5}{|l|}{ HIV-uninfected MSM } \\
\hline Age, $>46$ versus $\leq 46$ years ${ }^{*}$ & 3.77 (1.36 to 10.45$)$ & $3.70(1.30$ to 10.52$)$ & 1.07 (0.47 to 2.45 ) & \\
\hline Education, postgraduate versus undergraduate & $0.28(0.09$ to 0.88$)$ & 0.31 (0.09 to 1.00$)$ & 1.21 (0.53 to 2.74$)$ & \\
\hline \multicolumn{5}{|l|}{ Pack-years $†$} \\
\hline 0 & 1 & & 1 & \\
\hline $0.25-18$ & $0.21(0.04$ to 0.95$)$ & $0.21(0.05$ to 0.93$)$ & 1.13 (0.45 to 2.85$)$ & \\
\hline$>18$ & $1.02(0.22$ to 4.58$)$ & 0.50 (0.10 to 2.41$)$ & 0.74 (0.17 to 3.26 ) & \\
\hline \multicolumn{5}{|l|}{ Number of lifetime partners for any sex } \\
\hline$<50$ & 1 & & 1 & \\
\hline $50-150$ & 0.93 (0.27 to 3.24$)$ & & 1.09 (0.43 to 2.79$)$ & \\
\hline$>150$ & 1.42 (0.43 to 4.71$)$ & & 0.75 (0.23 to 2.46$)$ & \\
\hline Occasional partners for any sex, yes versus no & $1.86(0.24$ to 14.23$)$ & & $0.31(0.09$ to 1.10$)$ & \\
\hline \multicolumn{5}{|l|}{ Number of lifetime partners for oral sex } \\
\hline$<25$ & 1 & & 1 & \\
\hline $25-95$ & $0.49(0.12$ to 1.98$)$ & & 0.48 (0.18 to 1.27$)$ & \\
\hline$>95$ & 1.46 (0.48 to 4.39$)$ & & $0.63(0.22$ to 1.78$)$ & \\
\hline \multicolumn{5}{|l|}{ Number of recent partners for oral sex } \\
\hline$<3$ & 1 & & 1 & \\
\hline $3-6$ & $3.98(0.50$ to 31.62$)$ & & 0.90 (0.30 to 2.72$)$ & 0.93 (0.31 to 2.72$)$ \\
\hline$>6$ & $3.54(0.42$ to 29.67$)$ & & $0.18(0.05$ to 0.71$)$ & $0.18(0.05$ to 0.65$)$ \\
\hline Oral health/hygiene, poor versus good & 2.88 (1.04 to 7.99$)$ & 2.52 (0.88 to 7.27 ) & 1.36 (0.59 to 3.14$)$ & \\
\hline Oral care/condition, poor versus good & 1.06 (0.34 to 3.34$)$ & & 0.52 (0.09 to 3.09 ) & \\
\hline \multicolumn{5}{|l|}{ STI history } \\
\hline No & 1 & & 1 & \\
\hline Anogenital warts & 0.83 (0.17 to 3.93 ) & & 1.29 (0.47 to 3.52 ) & \\
\hline Other STIs & 2.40 (0.82 to 7.02 ) & & 0.93 (0.28 to 3.14$)$ & \\
\hline B) High-risk HPV & Incidence & & Clearance & \\
\hline HIV-infected MSM & $\begin{array}{l}\text { Univariate } \\
\text { HR }(95 \% \mathrm{Cl})\end{array}$ & Multivariate aHR $(95 \% \mathrm{Cl})$ & $\begin{array}{l}\text { Univariate } \\
\mathrm{HR}(95 \% \mathrm{Cl})\end{array}$ & Multivariate aHR $(95 \% \mathrm{CI})$ \\
\hline Age, $>46$ versus $\leq 46$ years $*$ & $1.64(0.47$ to 5.71$)$ & & & \\
\hline
\end{tabular}


Table 3 Continued

\begin{tabular}{|c|c|c|c|c|}
\hline \multirow{2}{*}{$\begin{array}{l}\text { B) High-risk HPV } \\
\text { HIV-infected MSM }\end{array}$} & \multicolumn{2}{|l|}{ Incidence } & \multicolumn{2}{|l|}{ Clearance } \\
\hline & $\begin{array}{l}\text { Univariate } \\
\text { HR }(95 \% \mathrm{Cl})\end{array}$ & Multivariate aHR $(95 \% \mathrm{Cl})$ & $\begin{array}{l}\text { Univariate } \\
\text { HR }(95 \% \mathrm{Cl})\end{array}$ & Multivariate aHR $(95 \% \mathrm{CI})$ \\
\hline \multicolumn{5}{|l|}{ Age (years) } \\
\hline$<36$ & 1 & & 1 & \\
\hline $36-46$ & n.e. & & $0.12(0.01$ to 1.09$)$ & $0.09(0.01$ to 0.79$)$ \\
\hline$>46$ & n.e. & & $0.09(0.01$ to 0.81$)$ & $0.04(0.01$ to 0.38$)$ \\
\hline Education, postgraduate versus undergraduate & 0.39 (0.08 to 1.87$)$ & & 0.59 (0.17 to 2.10$)$ & \\
\hline \multicolumn{5}{|l|}{ Pack-years } \\
\hline 0 & 1 & & 1 & \\
\hline $0.25-18$ & $0.48(0.05$ to 4.68$)$ & & $0.60(0.12$ to 3.10$)$ & \\
\hline$>18$ & $3.31(0.78$ to 14.01$)$ & & $1.37(0.38$ to 4.99$)$ & \\
\hline \multicolumn{5}{|l|}{ Number of lifetime partners for any sex } \\
\hline$<50$ & 1 & & 1 & \\
\hline $50-150$ & $3.79(0.39$ to 36.70$)$ & & $1.46(0.17$ to 12.18$)$ & \\
\hline$>150$ & 7.16 (0.86 to 59.70$)$ & & $1.45(0.23$ to 9.05$)$ & \\
\hline Occasional partners for any sex, yes versus no & $1.52(0.32$ to 7.21$)$ & & $1.41(0.40$ to 5.03$)$ & \\
\hline \multicolumn{5}{|l|}{ Number of lifetime partners for oral sex } \\
\hline$<25$ & 1 & & 1 & \\
\hline $25-95$ & 1.80 (0.16 to 20.03$)$ & & $2.65(0.27$ to 26.32$)$ & \\
\hline$>95$ & $5.80(0.71$ to 47.40$)$ & & $1.67(0.25$ to 11.10$)$ & \\
\hline \multicolumn{5}{|l|}{ Number of recent partners for oral sex } \\
\hline$<3$ & 1 & & 1 & \\
\hline $3-6$ & $1.15(0.27$ to 4.86$)$ & & $0.80(0.22$ to 2.93$)$ & \\
\hline$>6$ & $0.69(0.13$ to 3.54$)$ & & $1.37(0.25$ to 7.61$)$ & \\
\hline Condomless oral sex, yes versus no & 11.85 (2.38 to 58.96$)$ & $13.40(2.55$ to 70.53$)$ & n.e. & \\
\hline Oral health/hygiene, poor versus good & $0.36(0.07$ to 1.79$)$ & & $1.04(0.33$ to 3.24$)$ & \\
\hline Oral care/condition, poor versus good & $1.13(0.29$ to 4.41$)$ & & $0.57(0.17$ to 1.85$)$ & \\
\hline \multicolumn{5}{|l|}{ STI history } \\
\hline No & 1 & & 1 & \\
\hline Anogenital warts & $0.50(0.06$ to 4.15$)$ & & $0.70(0.09$ to 5.36$)$ & \\
\hline Other STIs & $1.21(0.30$ to 4.88$)$ & & $1.72(0.52$ to 5.67$)$ & \\
\hline Nadir CD4+T count, $<200$ versus $\geq 200$ cells $/ \mathrm{mm}^{3}$ & $1.30(0.27$ to 6.25$)$ & & $0.22(0.05$ to 0.99$)$ & $0.14(0.03$ to 0.75$)$ \\
\hline Current CD4+T count, $<500$ versus $\geq 500$ cells $/ \mathrm{mm}^{3}$ & $1.47(0.31$ to 7.14$)$ & & $0.39(0.11$ to 1.41$)$ & \\
\hline
\end{tabular}

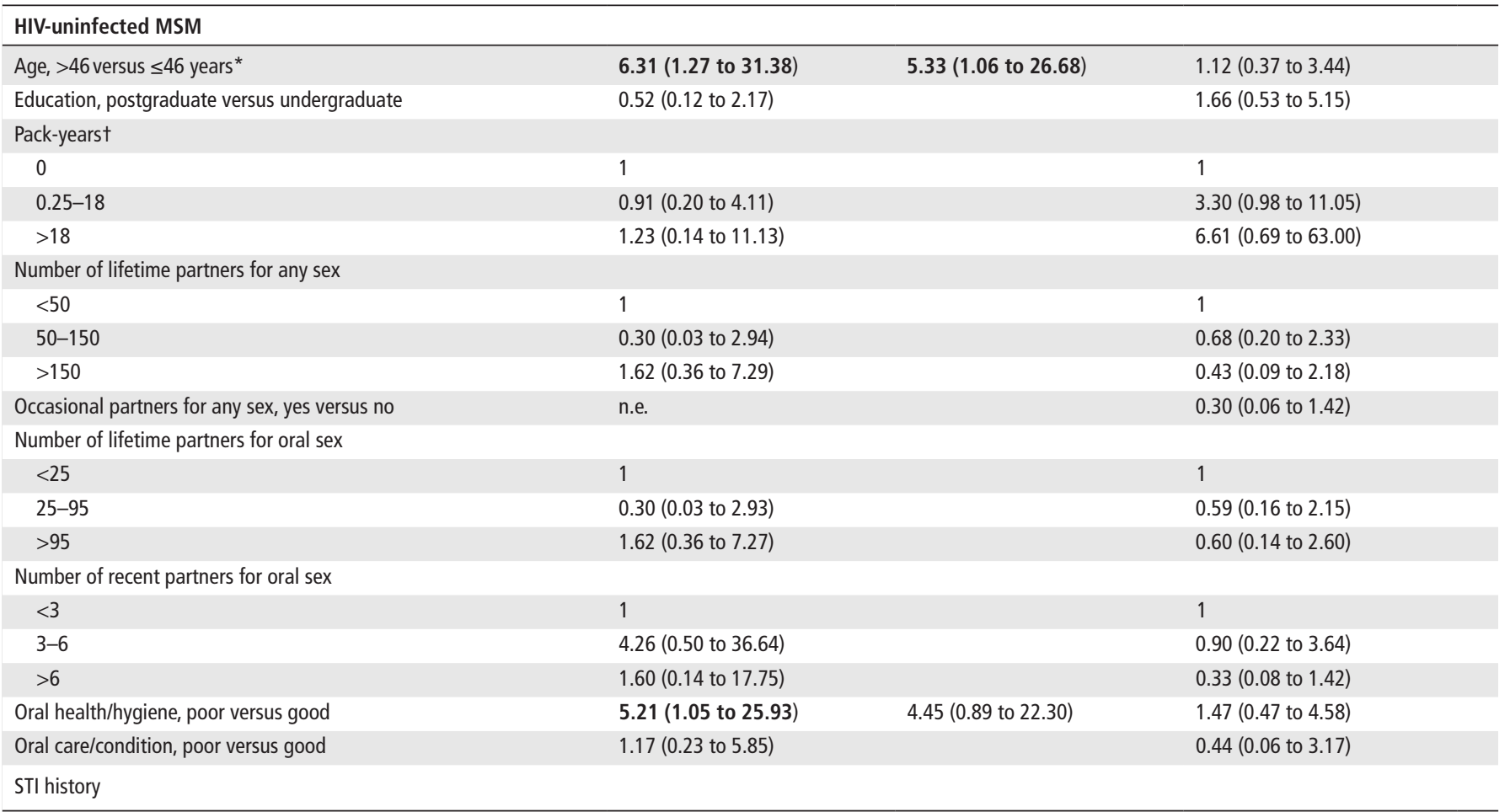




\begin{tabular}{lll}
\hline Table 3 Continued & & \\
\hline HIV-uninfected MSM & & \\
\hline No & 1 & 1 \\
Anogenital warts & $1.45(0.28$ to 7.52$)$ & $0.58(0.13$ to 2.68$)$ \\
Other STls & $0.62(0.07$ to 5.37$)$ & $1.97(0.45$ to 8.70$)$ \\
\hline
\end{tabular}

Only the variables that resulted significantly associated with incidence and/or clearance from the univariate analysis $(p<0.20)$ were included in the multivariable model (see Methods section for further details)

Condom use in oral sex was excluded from the analysis for HIV-uninfected MSM because the model did not converge.

Data in bold highlight statistically significant associations.

${ }^{*}$ Age, which was originally categorised into tertiles $(<36,36-46$ and $>46$ years), was recoded as a binary variable ( $\leq 46$ and $>46$ years) when the number of transitions for the category 36-46 years was too low to produce reliable estimates.

tSmoking, which was originally categorised into tertiles among smokers $(0.25-5.50,5.50-18$ and $>18$ pack-years), was recoded into two categories (0.25-18.0 and $>18$ packyears) since the number of transitions for the category $0.25-5.50$ was too low to produce reliable estimates.

¥Excluded from the multivariate analysis because of collinearity with number of lifetime partners for oral sex.

aHR, adjusted HR; HPV, human papillomavirus; MSM, men who have sex with men; n.e., not estimable; STI, sexually transmitted infection.

In the univariate analysis, incidence significantly increased in HIV-uninfected MSM aged $>46$ years and those with poor oral health/hygiene, whereas it declined in those with a higher educational level and those with $0.25-18.0$ pack-years of smoking compared with the respective reference categories. Individuals with a higher number of recent oral sex partners showed a significant decrease in clearance. Except for educational level and oral health/hygiene, the other associations were confirmed in multivariate analysis. Incidence was almost four times higher in those aged $>46$ years (aHR: $3.70,95 \%$ CI 1.30 to 10.52 ) and decreased significantly in those who had smoked $0.25-$ 18.0 pack-years (aHR: $0.21,95 \%$ CI 0.05 to 0.93 ). Clearance decreased significantly in those with more than six recent oral sex partners (aHR: $0.18,95 \%$ CI 0.05 to 0.65 ).

The results of the univariate and multivariate analyses for incidence and clearance of high-risk HPVs are shown in table 3B. In HIV-infected MSM, condomless oral sex was associated with more than a 10-fold increase in incidence (aHR: 13.40, 95\% CI: 2.55 to 70.53). Compared with MSM aged <36 years, those aged 36-46 years (aHR: 0.09 , 95\% CI 0.01 to 0.79 ) and $>46$ years (aHR: $0.04,95 \%$ CI 0.01 to 0.38 ) showed a reduced clearance. Clearance decreased significantly also in MSM with a nadir CD4+ T-cell count of $<200$ cells $/ \mathrm{mm}^{3}$ (aHR: $0.14,95 \%$ CI 0.03 to 0.75 ).

In HIV-uninfected MSM, only age was independently associated with high-risk HPV incidence, which increased significantly in older individuals (aHR: 5.33, 95\% CI 1.06 to 26.68 for those aged $>46$ vs $\leq 46$ years).

\section{DISCUSSION}

By reason of the need to improve our knowledge on the dynamics of oral HPV infection as well as the preventive efforts regarding HPV-associated OPC, longitudinal studies on individuals at higher risk of oral HPV play a key role.

Our incidence estimates for any and high-risk HPVs for the overall cohort are a dozen times higher than those calculated in a large population-based study conducted in China, ${ }^{20}$ most likely because of diverse sociodemographic characteristics and risk exposure of the study populations. Variability in oral sampling, HPV detection method, uncontrolled delay between consecutive visits and statistical analysis may also contribute to explaining the different rates. Despite the fact that almost all the HIV-infected MSM included in this investigation were successfully cART-treated, their incidence for any HPV and high-risk HPVs tended to be higher than those of HIV-uninfected MSM, consistently with other studies. ${ }^{15} 1718$ These observations seem to suggest that HIV infection favours oral HPV acquisition, although newly detected HPV may also result from reactivation of latent infections. HIV-infected subjects also showed a lower clearance of any HPV compared with the HIV-uninfected MSM, whereas the opposite was observed for high-risk HPVs. Taken together, these data might explain the higher prevalence of any HPV in the HIV-infected subjects of the OHMAR study and the similar prevalence observed for high-risk types in the two study groups. $^{21}$

The incidence rates for any and high-risk HPVs for HIVnegative MSM were approximately three times higher than those found in a cohort of HIV-negative and mostly heterosexual men. ${ }^{22}$ However, a recent meta-analysis found no evidence of an increased risk of oral HPV acquisition for MSM compared with heterosexual men. ${ }^{23}$

Noteworthy, incidence rates of oral infection by any and highrisk HPVs were much lower than those estimated for anal HPV in HIV-uninfected MSM ${ }^{19}$ and HIV-infected individuals. ${ }^{24}$ In contrast, clearance rates were higher for oral compared with anal infection. ${ }^{19}{ }^{24}$ Local immunity, risk of microtraumas, local environment (eg, salivary flow in the oral cavity), as well as type of sexual exposure, may be influential factors that explain differences in HPV acquisition and/or clearance at oral and anal levels.

Age affected HPV incidence and clearance differently in the two study groups. Incidence of any and high-risk HPVs increased with age in HIV-uninfected MSM, whereas clearance of any and high-risk HPVs decreased with age in the HIV-infected counterparts. Sexual behaviour at older age (eg, new partner acquisition, increased prevalence of partner concurrency), ${ }^{25}$ together with lower systemic and local immunity, may explain higher acquisition and lower clearance of oral HPV in older individuals. These observations, that is, an increase in acquisition on the one hand and a reduction of clearance with increasing age on the other hand, seem in line with the bimodal distribution of oral HPV prevalence in men, with a second peak in prevalence in older individuals, although this has been observed in mostly heterosexual men from the general population. ${ }^{26}$ However, association of incidence or clearance with age has not been observed consistently. Some studies found no association of incident oral infection with age. ${ }^{1824}$ Differently, the Persistent Oral Papillomavirus Study (POPS) study observed that any HPV incidence significantly decreased in older HIV-positive MSM and bisexual men, whereas clearance was reduced in older HIV-negative men. ${ }^{17}$

Unexpectedly, HIV-uninfected MSM who had smoked 0.25-18 pack-years showed a significantly lower incidence of any HPV compared with non-smokers. Other studies either did not observe any association of incidence/clearance with smoking ${ }^{171824}$ or evidenced a higher risk of acquiring oral HPV 
in smokers, ${ }^{22}$ although they regarded populations that were diverse for sex, sexual orientation and HIV status. Although smoking may favour HPV infection by promoting oral mucosa inflammation and suppressing local immunity, the smokingmediated induction of a protein involved in innate immunity has also been reported, ${ }^{27}$ and this may limit oral HPV acquisition.

There was statistical evidence that lifetime, for HIV-infected MSM, and recent, for HIV-uninfected MSM, number of oral sex partners affect acquisition and clearance of any HPV. Incidence increase with the number of lifetime oral sex partners is consistent with another investigation on HIV-infected MSM. ${ }^{17}$ Differently, clearance decline in HIV-uninfected MSM with a higher number of recent oral sex partners has not been observed in other studies, which found an association with incidence instead of clearance. ${ }^{15} 17$ Interestingly, association with lifetime sex behaviour for HIV-positive individuals and recent sex behaviour for HIV-negative subjects has also been reported for prevalent oral infection, ${ }^{13}$ suggesting that different parameters of MSM sexual behaviour can play a role in risk of oral HPV, depending on HIV status.

Risk of incident high-risk HPV infection increased more than 10 times in HIV-infected MSM who reported practice of condomless oral sex, in line with a report that showed that individuals who use barriers during oral sex have significantly reduced prevalence of oral HPV16/18. ${ }^{28}$ Since only a very small fraction of our participants always used condom during oral sex, so that very wide CIs were observed, our finding needs to be confirmed in larger studies.

Poor oral health/hygiene appeared to increase risk of any and high-risk HPV acquisition in HIV-uninfected MSM. Although an independent association was not confirmed, the role of poor oral hygiene in the risk of oral HPV infection is supported by cross-sectional studies. Poor oral health was an independent risk factor for the prevalence of oral HPV in an investigation on over 3000 individuals. ${ }^{29}$ It has been shown that poor oral hygiene also correlates with a higher prevalence of high-risk HPVs. ${ }^{30}$

MSM with nadir CD4+ T-cell count of $<200 / \mathrm{mm}^{3}$ displayed a significantly reduced clearance of high-risk HPVs, whereas neither incidence nor clearance was associated with this parameter in other studies. ${ }^{1724}$ We did not observe any association with current CD4+ T-cell count, in line with others, ${ }^{18}$ but differently from the POPS study, which evidenced a higher incidence of oral infection in those with a lower current CD4+ T-cell count. ${ }^{17}$ Immunosuppression in HIV-infected subjects thus appears to affect the natural history of oral HPV infection, but data are inconsistent.

Some strengths of the study can be noted. The use of a Markov model allowed us to produce more accurate estimates for incidence and clearance compared with person-time analyses.

\section{Key messages}

- Acquisition of oral human papillomavirus (HPV) infection in men who have sex with men (MSM) is 4 to 12 times less frequent than the respective clearance.

- Older age is associated with increased incidence in HIVuninfected MSM and decreased clearance in HIV-infected MSM.

- Different parameters of sexual behaviour affect incidence and clearance of oral HPV, depending on the HIV status.

- Clearance of high-risk HPVs in HIV-infected MSM decreases with nadir CD4+ Tcell count.
Behavioural data were collected also at follow-up visits, differently from most previous studies, enabling us to handle patient shifts across categories of risk and to provide more accurate risk estimates. Both HIV-infected and HIV-uninfected subjects were included, so that possible effects of the HIV status on oral HPV natural history could be explored.

This study also has some limitations. An HPV-negative test does not necessarily mean clearance. This represents a limit of the definition of HPV infection based on HPV-DNA testing, since undetectability may be due to a low viral load (below the test detection limit) instead of true clearance. Due to lack of transitions, type-specific estimates were not provided for all high-risk HPVs. The power was probably insufficient to evidence significant associations for some covariates, for example, oral health/ hygiene. In addition, despite the fact that the rating system for oral health/hygiene was established by expert otolaryngologists, a subjective component may have affected the evaluation. The possible role of some covariates as risk factors could not be explored because they had to be excluded from the analysis when the model did not converge. Because of the limited sample size, the overall precision of some estimates may be considered weak, also because of the wide categories used for some variables (eg, pack-years). Our findings should be thus confirmed in larger studies. Finally, our findings may not be generalisable to hard-toreach and most-at-risk subgroups of MSM.

In conclusion, we observed that in our cohort oral HPV acquisition occurs rarely, whereas clearance is frequent. Among HIVinfected MSM, a high number of lifetime oral sex partners and condomless oral sex appeared to be the strongest predictors for incident infection by any and high-risk HPVs, respectively. Older age showed a strong independent association with incidence in HIV-uninfected MSM and clearance in the HIV-infected counterparts. Further efforts should be made to clarify the natural history of oral HPV, in particular, to identify the factors that could affect the persistence of high-risk HPVs.

\section{Handling editor Jason J Ong}

Acknowledgements The authors acknowledge Dr Michael Kenyon for his review of the English language.

Contributors Study conception and design: MGD, MG and AC; data acquisition and interpretation: MG, FR, BP, AL, MB, RP and MGD; data analysis: MG, MFV and MGD; manuscript drafting: MGD, MG and MFV; critical revision and final approval of the manuscript: $F R, B P, A L, M B, R P$ and $A C$

Funding This work was supported by the Italian Ministry of Health (grant number GR-2011-02349732) (to MGD)

Competing interests $\mathrm{MB}$ received non-financial support from Roche Diagnostics and Hologic outside the submitted work.

\section{Patient consent for publication Not required.}

Ethics approval Written informed consent was obtained from the participants. All procedures were performed in accordance with the Helsinki Declaration. The study was cleared by the institutional Ethics Committee (CE/417/14).

Provenance and peer review Not commissioned; externally peer reviewed.

Data availability statement Data are available upon reasonable request. Database of this study includes results of molecular tests and deidentified, mostly sensitive, participant data.

\section{ORCID iDs}

Alessandra Latini http://orcid.org/0000-0002-9421-6560

Maria Gabriella Dona' http://orcid.org/0000-0003-3250-1726

\section{REFERENCES}

1 Castellsagué $\mathrm{X}$, Alemany $\mathrm{L}$, Quer $\mathrm{M}$, et al. Hpv involvement in head and neck cancers: comprehensive assessment of biomarkers in 3680 patients. J Nat/ Cancer Inst 2016;108:djv403 
2 de Martel C, Plummer M, Vignat J, et al. Worldwide burden of cancer attributable to HPV by site, country and HPV type. Int J Cancer 2017;141:664-70.

3 Tinhofer I, Jöhrens K, Keilholz U, et al. Contribution of human papilloma virus to the incidence of squamous cell carcinoma of the head and neck in a European population with high smoking prevalence. Eur J Cancer 2015;51:514-21.

4 Haeggblom L, Attoff T, Yu J, et al. Changes in incidence and prevalence of human papillomavirus in tonsillar and base of tongue cancer during 2000-2016 in the Stockholm region and Sweden. Head Neck 2019;41:1583-90.

5 Wittekindt C, Wagner S, Bushnak A, et al. Increasing incidence rates of oropharyngeal squamous cell carcinoma in Germany and significance of disease burden attributed to human papillomavirus. Cancer Prev Res 2019;12:375-82.

6 Tam S, Fu S, Xu L, et al. The epidemiology of oral human papillomavirus infection in healthy populations: a systematic review and meta-analysis. Oral Oncol 2018;82:91-9.

7 Mena M, Taberna M, Monfil L, et al. Might oral human papillomavirus (HPV) infection in healthy individuals explain differences in HPV-Attributable fractions in oropharyngeal cancer? A systematic review and meta-analysis. J Infect Dis 2019;219:1574-85.

8 Mooij SH, Boot HJ, Speksnijder AGCL, et al. Oral human papillomavirus infection in HIV-negative and HIV-infected MSM. AIDS 2013;27:2117-28.

9 King EM, Gilson R, Beddows S, et al. Oral human papillomavirus (HPV) infection in men who have sex with men: prevalence and lack of anogenital concordance. Sex Transm Infect 2015;91:284-6.

10 Rollo F, Latini A, Pichi B, et al. Prevalence and determinants of oral infection by human papillomavirus in HIV-infected and uninfected men who have sex with men. PLoS One 2017; 12:e0184623.

11 Parisi SG, Cruciani M, Scaggiante R, et al. Anal and oral human papillomavirus (HPV) infection in HIV-infected subjects in northern Italy: a longitudinal cohort study among men who have sex with men. BMC Infect Dis 2011;11:150.

12 Read TRH, Hocking JS, Vodstrcil LA, et al. Oral human papillomavirus in men having sex with men: risk-factors and sampling. PLoS One 2012;7:e49324.

13 Beachler DC, Weber KM, Margolick JB, et al. Risk factors for oral HPV infection among a high prevalence population of HIV-positive and at-risk HIV-negative adults. Cancer Epidemiol Biomarkers Prev 2012;21:122-33.

14 Darwich L, Cañadas MP, Videla S, et al. Oral human papillomavirus type-specific infection in HIV-infected men: a prospective cohort study among men who have sex with men and heterosexual men. Clin Microbiol Infect 2014;20:0585-9.

15 van Aar F, Mooij SH, van der Sande MAB, et al. Twelve-month incidence and clearance of oral HPV infection in HIV-negative and HIV-infected men who have sex with men: the H2M cohort study. BMC Infect Dis 2014;14:668.
16 Ong JJ, Read TRH, Vodstrcil LA, et al. Detection of oral human papillomavirus in HIV-positive men who have sex with men 3 years after baseline: a follow up crosssectional study. PLoS One 2014;9:e102138.

17 Beachler DC, Sugar EA, Margolick JB, et al. Risk factors for acquisition and clearance of oral human papillomavirus infection among HIV-infected and HIV-uninfected adults. Am J Epidemiol 2015;181:40-53.

18 Mooij SH, Boot HJ, Speksnijder AGCL, et al. Six-Month incidence and persistence of oral HPV infection in HIV-negative and HIV-infected men who have sex with men. PLoS One 2014;9:e98955.

19 Donà MG, Vescio MF, Latini A, et al. Anal human papillomavirus in HIV-uninfected men who have sex with men: incidence and clearance rates, duration of infection, and risk factors. Clin Microbiol Infect 2016;22:1004.e1-1004.e7.

20 Zhang C, Liu F, Pan Y, et al. Incidence and clearance of oral human papillomavirus infection: a population-based cohort study in rural China. Oncotarget 2017:8:59831-44

21 Rollo F, Pichi B, Benevolo M, et al. Oral testing for high-risk human papillomavirus DNA and E6/E7 messenger RNA in healthy individuals at risk for oral infection. Cancer 2019;125:2587-2593.

22 Kreimer AR, Pierce Campbell CM, Lin H-Y, et al. Incidence and clearance of oral human papillomavirus infection in men: the him cohort study. The Lancet 2013;382:877-87.

23 King EM, Oomeer S, Gilson R, et al. Oral human papillomavirus infection in men who have sex with men: a systematic review and meta-analysis. PLoS One 2016;11:e0157976.

24 Beachler DC, D'Souza G, Sugar EA, et al. Natural history of anal vs oral HPV infection in HIV-infected men and women. J Infect Dis 2013;208:330-9.

25 Glick SN, Morris M, Foxman B, et al. A comparison of sexual behavior patterns among men who have sex with men and heterosexual men and women. J Acquir Immune Defic Syndr 2012;60:83-90.

26 Gillison ML, Broutian T, Pickard RKL, et al. Prevalence of oral HPV infection in the United States, 2009-2010. JAMA 2012;307:693-703.

27 Quabius ES, Görögh T, Fischer GS, et al. The antileukoprotease secretory leukocyte protease inhibitor (SLPI) and its role in the prevention of HPV-infections in head and neck squamous cell carcinoma. Cancer Lett 2015;357:339-45.

28 Gupta A, Perkins RB, Ortega G, et al. Barrier use during oro-genital sex and oral human papillomavirus prevalence: analysis of NHANES 2009-2014. Oral Dis 2019:25:609-16.

29 Bui TC, Markham CM, Ross MW, et al. Examining the association between oral health and oral HPV infection. Cancer Prev Res 2013:6:917-24.

30 Dalla Torre D, Burtscher D, Sölder E, et al. The correlation between the quality of oral hygiene and oral HPV infection in adults: a prospective cross-sectional study. Clin Oral Investig 2019;23:179-85. 